\title{
Deep Space Habitat ECLSS Design Concept
}

\author{
Su Curley ${ }^{*}$ Imelda Stambaugh ${ }^{\dagger}$, Michael Swickrath ${ }^{\ddagger}$, Molly S. Anderson ${ }^{\S}$, and Henry Rotter ${ }^{* *}$ \\ National Aeronautics and Space Administration, Houston, TX, 77058
}

\begin{abstract}
Life support is vital to human spaceflight, and most current life support systems employ single-use hardware or regenerable technologies that throw away the waste products, relying on resupply to make up the consumables lost in the process. Because the long-term goal of the National Aeronautics and Space Administration is to expand human presence beyond low-earth orbit, life support systems must become self-sustaining for missions where resupply is not practical. From May through October 2011, the life support team at the Johnson Space Center was challenged to define requirements, develop a system concept, and create a preliminary life support system design for a non-planetary Deep Space Habitat that could sustain a crew of four in near earth orbit for a duration of $\mathbf{3 8 8}$ days. Some of the preferred technology choices to support this architecture were passed over because the mission definition has an unmanned portion lasting 825 days. The main portion of the architecture was derived from technologies currently integrated on the International Space Station as well as upcoming technologies with moderate Technology Readiness Levels. The final architecture concept contains only partially-closed air and water systems, as the breakeven point for some of the closure technologies was not achieved with the mission duration.
\end{abstract}

\section{Introduction}

Tn late spring of 2011, the Spacecraft Design Office was tasked with developing a concept Deep Space Habitat 1 (DSH) vehicle that would support a mission with a crew of four for 388 days while traversing from Low Earth Orbit (LEO) to a Near Earth Object (NEO), specifically the asteroid 2008 EV5. The DSH would be launched unmanned, mated with a Space Exploration Vehicle (SEV), and loiter in High Earth Orbit up to 825 days until the crew arrives aboard the Multi-Purpose Crew Vehicle (MPCV). The crew would live in the DSH as the stack of vehicles transitions to the asteroid, loiters while the SEV performs sortie missions, and returns to Leo Earth Orbit where the crew will transfer back to the MPCV for return to earth and tSehe DSH will be jettisoned, as represented in Figure 1.

The effort to develop this concept was sponsored by the Human Spaceflight Architecture Team, which was examining a broad range of mission architectures and vehicles, and was designed to complement the parametric studies being performed. The process of developing more detailed requirements, interfaces, and operating concepts for the 2008 EV5 mission revealed many drivers for the life support system design.

\footnotetext{
* Senior Life Support Engineer, Crew and Thermal Systems Division, 2101 NASA Parkway/ EC3, Houston, TX, 77058, AIAA Member

${ }^{\dagger}$ Life Support Engineer, Crew and Thermal Systems Division, 2101 NASA Parkway/ EC2, Houston, TX, 77058, AIAA Member.

${ }^{\ddagger}$ Analyst, Crew and Thermal Systems Division, 2101 NASA Parkway/ EC2, Houston, TX, 77058, AIAA Member.

${ }^{\S}$ Life Support and Systems Engineer, Crew and Thermal Systems Division, 2101 NASA Parkway/ EC2, Houston, TX, 77058, AIAA Member.

** ECLSS Architect, Crew and Thermal Systems Division, 2101 NASA Parkway/ C104, Houston, TX, 77058, AIAA Member.
} 


\section{Full Capability NEO: 2008 EV5 NEO Crewed Mission Hybrid \#02}

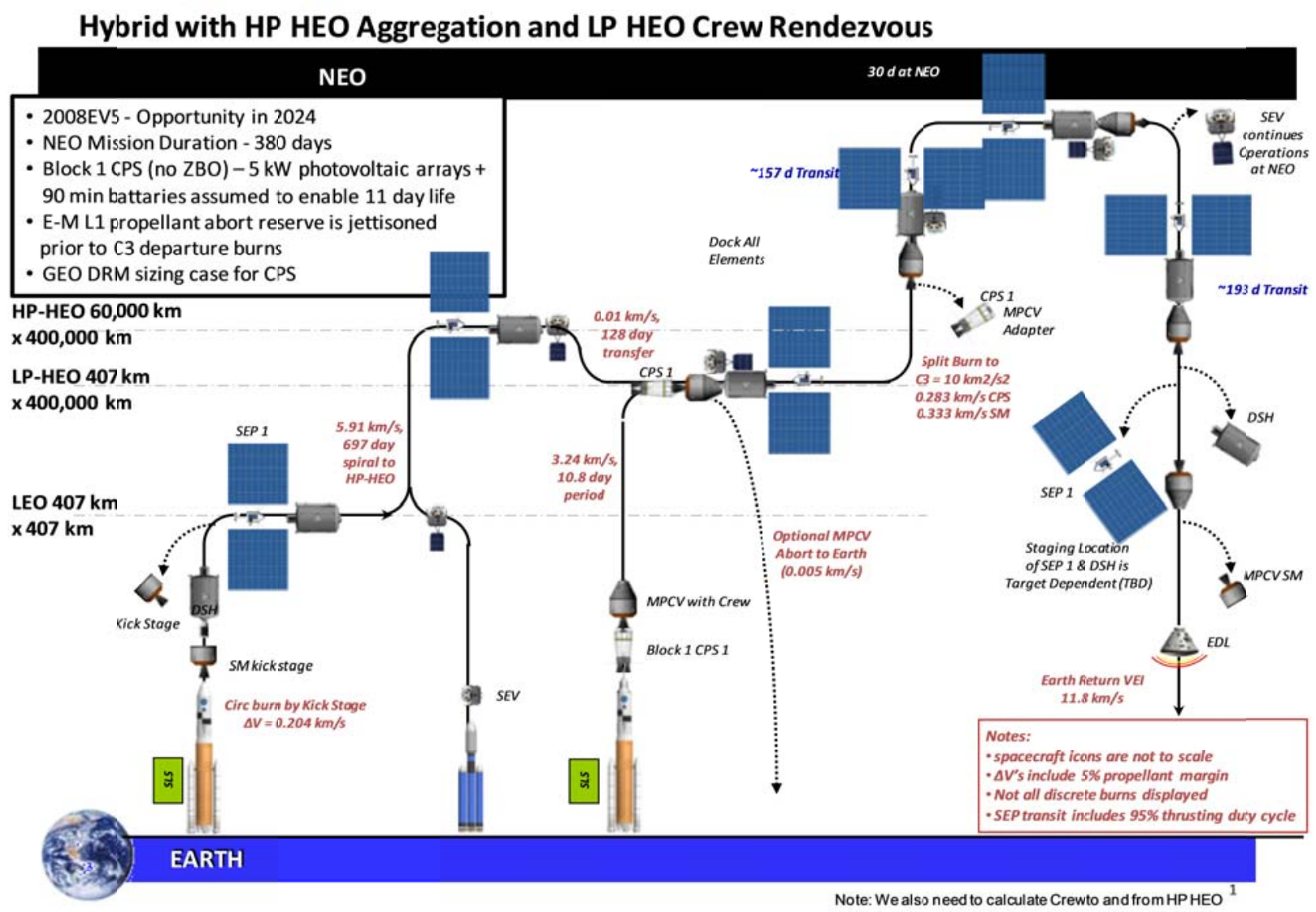

Figure 1. Mission Timeline for a Full Capability Mission to Asteroid 2008 EV5

\section{ECLSS Requirements}

The mission timeline provided key driving requirements for the DSH architecture and performance, and it significantly influenced the baseline design of the Environmental Control and Life Support System (ECLSS). With such a long mission duration, the life support team had to evaluate to what level of closure the ECLSS should be to prevent loss of crew or mission due to hardware failures while keeping the mass and volume as low as practical. The large unmanned portion of the mission immediately narrowed the technology choices for the water recovery system, which would not be able to sustain a biological water processor during that long latency period. With no resupply of consumables, the amine-based, vacuum desorb, carbon dioxide removal technology baselined for both the MPCV and the SEV could not be utilized in the air revitalization system, thereby causing the DSH to process the atmosphere for the entire stack after the crew arrives. Also, in addition to carrying enough consumables to resupply the MPCV upon arrival for emergency escape and the SEV for two, seven-day excursions for exploration, the DSH must have contingency Extra-Vehicular Activity (EVA) capability and Portable Life Support System (PLSS) recharge.

\section{Technology Research and Trades}

The ECLSS was divided into six major areas: air revitalization, water recovery, waste management, pressure control, fire detection and response, and Extra-Vehicular Activity (EVA) support. The basic functions of each of these were defined, and the specific requirements to meet those functions were largely taken from the Constellation Human Systems Integration Requirements (HSIR) document. Several technology options were examined for each subsystem, and long term cost effectiveness, quick response performance, and physical layout impacted the selections in each system. 
The water recovery technologies that were considered included the biological systems already discussed and several distillation based physico-chemical systems. The International Space Station (ISS) uses a urine distillation system currently recovering $70 \%$ of the input water, but the performance of this system may achieve $85 \%$ recovery by using a technology that removes calcium or sulfuric acid from the urine or by using pretreatment chemicals.

Air revitalization system options include single-use options like Lithium Hydroxide ( $\mathrm{LiOH})$ canisters, regenerable swing bed systems that dump carbon dioxide $\left(\mathrm{CO}_{2}\right)$ and water vapor to space vacuum, and regenerable systems that separate and store $\mathrm{CO}_{2}$ and water. For long duration missions, single-use options may not seem sensible, but they could be used as emergency backup, depending upon the available stowage volume. The need to recycle condensate for the water balance is the primary driver in deciding between a system that regenerates by evacuating to space and a system that separates and saves the products. If water must be recovered, humidity control is accomplished with a condensing heat exchanger and phase separator. If $\mathrm{CO}_{2}$ is collected separately, several options for $\mathrm{CO}_{2}$ reduction to recover oxygen are available, including Sabatier reactors with and without methane pyrolysis downstream, and a range of approaches to Bosch process reactors. Selections between all of these systems are largely driven by the appropriate level of resource recovery for this mission. The way the technologies are implemented can depend strongly on the layout of the vehicle and operation during contingency scenarios.

Waste management systems include the components to collect solid and liquid waste from the crew and to process, store, or recover resources from it. The design of the commode or urinal for collection is desired to be common with other vehicles so that crew training is consistent and replacement parts or consumables can be shared. Depending on the level of resource recovery required and what can be cost effectively acheived, storage, compaction, drying, pyrolysis, or incineration technologies could all be considered.

The pressure control system needs to be designed for both nominal and contingency scenarios, as well as pressure equalizations with mating vehicles. In nominal operation, the one critical choice to be made is the selection of the set points for total pressure and oxygen partial pressure. Oxygen generation in contingency operations, maintaining cabin pressure during leak scenarios, and possibly depressurizing or repressurizing after other contingencies needs to be considered.

New fire detection and suppression technologies are in development for spaceflight applications, but the team also needed to consider the recovery of the vehicle after a fire event. Plans must be developed for crew safe haven location and recovery of the atmosphere.

The Deep Space Habitat supports contingency EVAs in the event that the DSH has a breech after the SEV leaves. Trade studies need to consider how to provide fluids (like water and oxygen) as well as what physical interfaces are needed (like airlocks or umbilical connections).

The team performed several kinds of trade studies to find the optimal design for this spacecraft. Parametric studies helped find the appropriate level of loop closure. The mass, volume, and power of new technologies was compared to existing options to perform those functions. The physical layout of the spacecraft was analyzed to find the best placement to integrate the systems across the vehicle. Finally, contingency cases were considered to make sure sufficient components, and the most efficient components, would be available for mission critical and life critical functions after failure.

\section{A. Equivalent System Mass Analysis}

A basic life support system architecture, based upon both physiochemical systems currently employed aboard the ISS and upcoming technologies with moderate Technology Readiness Level (TRL), was assessed using equivalent system mass (ESM) as the cost function for comparison. This metric has heritage in life support system analysis tracing back to the defining efforts of Levri and colleagues ${ }^{1,2}$. Specifically, ESM quantifies the life support system hardware, infrastructure, and consumables mass $(M)$, along with accounting for mass penalties -or- cost equivalencies $\left(c_{P}, c_{Q}, c_{V}\right.$, and $\left.c_{t}\right)$ associated with power $(P)$, cooling $(Q)$, volume $(V)$, and crew-time requiments $(t)$ according to eq.(1). The mass penalties are applied using spacecraft and mission specific cost factors related to power generation equipment, active and passive thermal control technology, habitat materials and shielding, and anticipated hardware maintenance. The product of each cost factor and associated term results in the ESM for each architecture under a given set of mission constraints.

$$
\mathrm{ESM}=M+c_{P} P+c_{V} V+c_{Q} Q+c_{t} t
$$

It is worth mentioning that ESM results should not be employed as the sole metric to assess the favorability of competing life support systems. For example, Jones ${ }^{3}$ notes that the analysis implicitly assumes equipment achieves nominal performance neglecting start-up and shut-down transients. Furthermore, Levri ${ }^{1}$ states the caveat that ESM 
alone does not account for additional critical specifications such as reliability or safety of a particular component or subsystem. Accordingly, ESM in this analysis serves only as an indicator to draw broad conclusions regarding the applicability of the life support system architectures presented in this work. Consequently, the authors suggest that the ESM results are an indicator of the economics of each system although other criteria need to be considered in the down-selection process such as safety, reliability, complexity, commonality, maturity, and maintainability of the system components.

\section{B. Mission Specification and Cost Equivalency Assumptions}

For this analysis, the architecture of the DSH for a crew of four was investigated for a mission of 100-900 days in duration in order to identify break-even points in technology trades. A volume cost equivalency was applied assuming a hard-shell habitat. Solar photovoltaics with fuel cell storage was assumed as the primary means of harvesting energy. Thermal control was presumed to be achieved using flow-through radiators. Crew time costs were assessed according to the anticipated hours available for the crew to perform maintenance activities for a given mission duration. This number was divided by the total mass of consumables, hardware, and infrastructure for the sized vehicle to provide the mission and configuration specific crew time cost equivalency. The cost equivalency was subsequently applied to the actual expected crew hours required for maintenance of the defined configuration. As a result of these characteristics of the craft, cost equivalencies are summarized in Table 1.

Table 1. Cost equivalencies applied in this analysis.

\begin{tabular}{|l|r|l|}
\hline Cost Factor Attribute & Value & Units \\
\hline Volume, hard shell habitat & 66.7 & $\mathrm{~kg} / \mathrm{m}^{3}$ \\
\hline Power, solar voltaic with fuel cell storage & 237.0 & $\mathrm{~kg} / \mathrm{kW}$ \\
\hline Thermal, flow-through radiators & 40.0 & $\mathrm{~kg} / \mathrm{kW}$ \\
\hline Crew time, architecture specific & $*$ & $\mathrm{~kg} / \mathrm{CM}-\mathrm{hr}$ \\
\hline
\end{tabular}

* The crew time cost equivalency is calculated according to the specific life support architecture configuration.

In addition, it is worth mentioning that extra-vehicular activity (EVA) was presumably minimal. For missions up to 900 days, only one week of EVA was performed directly from the DSH. This assumption had a signicant impact on the water balance since it eliminates the demand on the water supply for EVA related evaporative cooling.

A variety of open, partially-closed, and closed loop architectures were analyzed comparing overall recovery efficiencies for the water system and the efficiency through which carbon dioxide is utilized to feed back into the air subsystem. The analysis also provided cases with and without laundry as well as a variety of oxygen generation and carbon dioxide reduction options.

Using the cost factors detailed above, the return on investment for the different architectures was evaluated and compared, as shown in Figure 2. Breakeven points for the open loop and partially closed loop architectures lie close to the 2008 EV5 mission duration, but, most notably, the ESM for the closed loop architectures was considerably higher than those for the open or partially closed systems. This ESM is very large for these architectures because of the power assumption for the plasma reaction and the values may come down as the technology matures. The breakeven dates identified agree well with those of Jones ${ }^{4}$ for systems employing both carbon dioxide reduction and oxygen generation systems utilizing a urine processor. 


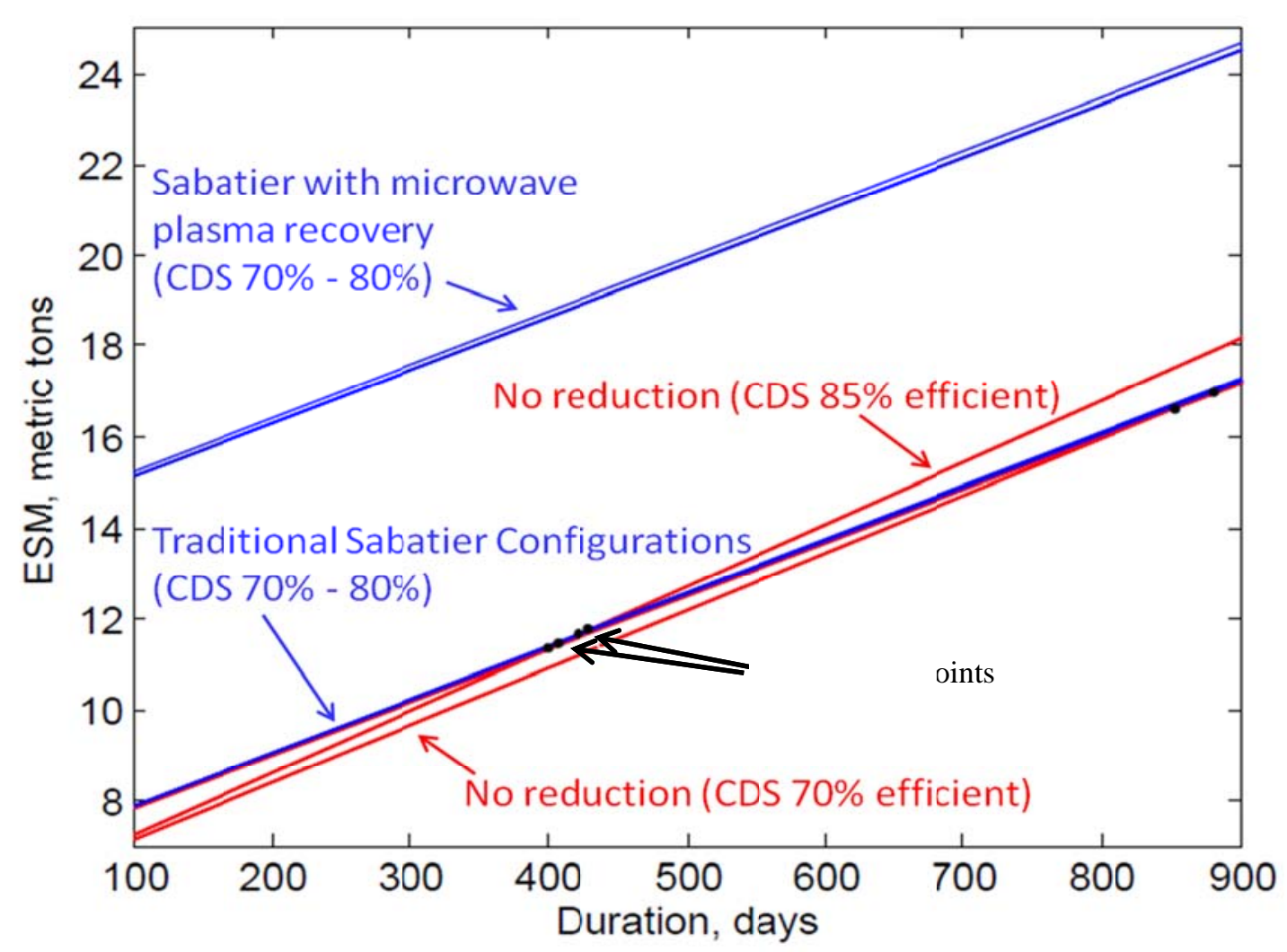

Figure 2. Break-even analysis between open, partially closed, and fully closed life support systems

\section{Post-fire response study}

Post-fire atmospheric clean up is essential to remove toxic gases and smoke from the habitat in order to make the atmosphere viable for the crew. After a fire, the atmosphere can contain the following contaminants: smoke, soot, fine particulates, carbon monoxide, acid gases, and volatile organic compounds. These contaminants could be a hazard to the crew, could poison catalyst beds used to control contaminants, or could clog clean up filtration. A study was conducted to compare depressurizing/repressurizing (D\&R) the DSH atmosphere after a fire event versus using a post-fire gas removal system ${ }^{\dagger \dagger}$. The study considered mass, power, volume, and design maturity of post-fire clean up hardware and recommended the type of post-fire clean up hardware needed for the DSH.

The study assumed that the time to vent and restore the atmosphere to the entire DSH volume would be 48 hours, as single floors could not be vented separately due to the pressure differential across the floor structures themselves. Therefore, the study concluded that the Fixed Smoke Eater would be capable of post fire clean up in less than two hours and had the lowest total mass and the smallest volume, versus D\&R or a portable system, and warrants further investigation. The Fixed Smoke Eater has the highest design complexity over already certified flight hardware.

Additionally, the study evaluated both the Air Revitalization System (ARS) design and operation. During a post fire scrub, it is essential that the crew is protected from toxic fire products. To accommodate this, the study suggested that the ARS should be deactivated to minimize oxygen available for the fire and the modules should be isolated to prevent dispersion. But if the crew remains in an isolated portion of the DSH, the deactivation of the ARS could lead to an increase in $\mathrm{CO}_{2}$ concentrations since the metabolic $\mathrm{CO}_{2}$ would not be scrubbed from the atmosphere. Therefore, the study recommended that the ventilation system design provide for the normal operation of the ARS in unaffected areas or the safe haven while allowing for the post fire scrub in the module(s) affected by the fire.

I† Hummel, K., “Deep-Space Hab (DSH) Fire Response Scenarios Study Results”, Microsoft PowerPoint presentation, September 21, 2011.

American Institute of Aeronautics and Astronautics 


\section{Feed-the-Leak Analysis}

The most credible threat to the integrity of the DSH structure is micrometeoroid impact. If the hull of the DSH were breached, the crew would have two options: try to stay and repair the damage or evacuate. Staying raised the questions of how big of a hole would the pressure control system be able to cover and how long could the system feed the leak. The answers to the first two questions were relevant to the discussion of crew evacuation, and if the crew did seek shelter in the MPCV, the question was raised whether the DSH could be used to accommodate survival in the MPCV in order to return the crew safety from Near Earth Asteriod (NEA). In order to answer these questions, a feed-the-leak analysis was performed.

The nominal spacecraft pressure is planned at $10.2 \mathrm{psia}$, and the analysis evaluated the time for the DSH volume to simply decay from 10.2 psia to 8 psia for a $1 / 4$-inch, $1 / 2$-inch, and 3/4-inch holes without providing any make up gas. Results of this study are summarized in Table 2. To determined the realistic feed-the-leak requirement, the team drew upon Space Shuttle heritage using a $1 / 4$-inch breach as the defining size. With this, the resulting 3.5 hour time to effect for the $1 / 4$-inch breach was more than adequate for the to crew get into a safe haven, don a pressurized suit, identify the leak location, and possibly even repair the leak. As a result, this analysis determined that the ECLSS did not need to carry additional gas to support a feed-the-leak scenario.

Table 2. Amount of time for DSH to depress to 8 psia after hull breach

\begin{tabular}{|c|c|}
\hline $\begin{array}{c}\text { Hole Size } \\
\text { (inches) }\end{array}$ & $\begin{array}{c}\text { Time from 10.2 to } \\
\text { 8 psia (minutes) }\end{array}$ \\
\hline 0.25 & 212 \\
\hline 0.50 & 52 \\
\hline 0.75 & 23 \\
\hline
\end{tabular}

If the crew had to evacuate the DSH and seek shelter within the MPCV, the worst-case scenario would be when the crew is at the asteroid (193 day transit from Earth). The DSH would depress, but in order to accommodate the crew within the MPCV, the life support system within the DSH would have to continue operating. To do this, some redesign would be needed; specifically the MPCV hatch would require penetrations to send waste water out to the DSH processors and send potable water and oxygen back to the crew. In this configuration, the water processor would have to function in a vacuum. The radiation protection "water wall" would also freeze, but this would not matter unless the water/ice could damage needed equipment or this water would be required to supply the consumables to support the crew. Additionally, the MPCV control system would have to be designed to control all needed DSH functions.

Because the volume of the MPCV is small, crew provisions (such as food, hygiene, batteries, etc) would still be stored within the DSH. Large umbilicals would be needed in order for the crew to don suits, depress the MPCV, and retrieve the necessary supplies. The feed-the-leak analysis evaluated this scenario and determined that approximately 17 depress/repress cycles would be required to accommodate this. While the quantity of gas necessary to repress one full DSH volume was already accounted for in the total consumable numbers for the vehicle, adding the capability to sustain the crew return from NEA in the MPCV would require a large increase in the total consumable mass and volume to be launched with the DSH. In the end, it was determined by the vehicle team that designing the system for the crew return from a NEA was and unrealistic.requirement to place on ECLSS.

\section{The Design Concept}

With the results from the analysis of the various architectures, the overall ECLSS design concept for the DSH is a combination of consumable storage and partially-closed recycling system, which is in agreement with a study from Jones $^{9}$. The details of each of the six subsystems are described below. 


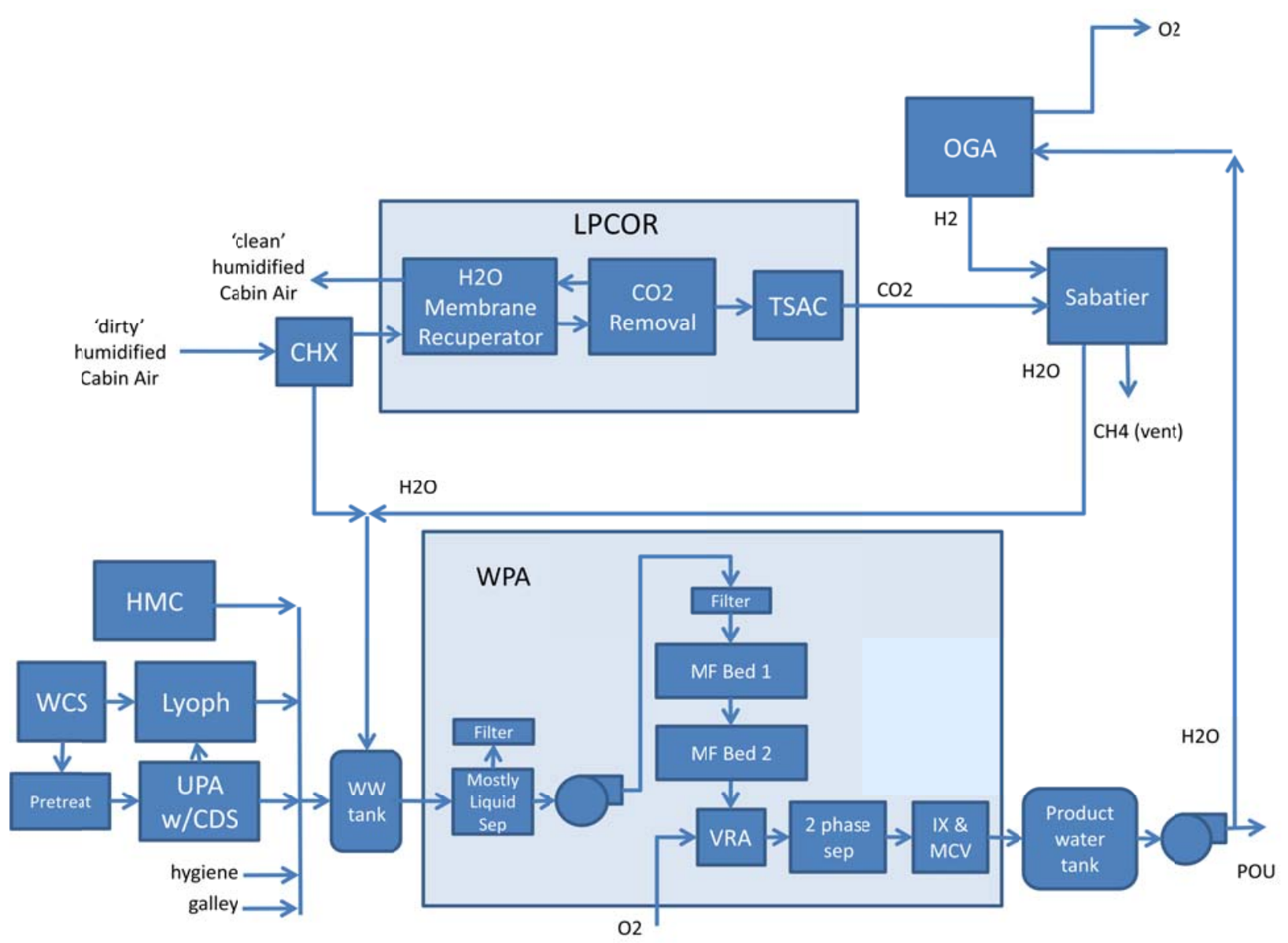

Figure 3. Integrated Air and Water Systems Concept

\section{A. Air Revitalization System}

As it is not practical to carry all of the necessary oxygen to provide pressure control and to support metabolic consumption during the mission, the air revitalization system relies on the state-of-the-art (SOA) ISS Oxygen Generation Assembly (OGA) water electrolysis system to provide the necessary $\mathrm{O}_{2}$. Using water to generate $\mathrm{O}_{2}$ drove the need to recover as much water as practical, and as such, drove the design away from $\mathrm{CO}_{2}$ technologies that are single-use or are regenerable by desorbing to space vacuum, even though the latter is baselined for both the MPCV and MMSEV vehicles and would provide commonality between all of the systems.

Like the ISS analog, the DSH air system uses a condensing heat exchanger to control humidity and remove water from the air stream prior to entering the carbon dioxide removal technology. Water is condensed from the air stream and sent to the waste water tank for subsequent processing by the water recovery system. Unlike the ISS, which has had problems providing the resources to support the crew of six due to continued problems with the Carbon Dioxide Removal Assembly (CDRA) ${ }^{5}$, the DSH utilizes the Low Power Carbon Dioxide Removal (LPCOR) ${ }^{6}$ system to remove $\mathrm{CO}_{2}$ from the cabin air and supply it to the SOA Sabatier processor. While the LPCOR uses the same zeolite 5A as the CDRA for $\mathrm{CO}_{2}$ absorption, the water remaining in the air stream after the condensing heat exchanger is removed by a combination of a Nafion membrane bulk dryer and a Novelaire desiccant residual dryer. This change provides nearly a 1/2 ESM savings over the CDRA ${ }^{7} \cdot \mathrm{CO}_{2}$ removed from the cabin air is then sent to the Sabatier processor (Figure 3). The ESM analysis determined that adding reduction systems to recover hydrogen is too high with little to no improvement in water recovery. It was determined to be far cheapers to provide a small supply of hydrogen to feed the Sabatier system. The ESM penalty for loop-closure technologies will likely reduce as the technologies mature. 


\section{B. Water Recovery System}

The DSH is required to replenish the consumables for both the MPCV (to allow for emergency escape after it arrives) and the MMSEV, which doesn't have the volume to store all of the consumables needed for the SORTIE missions. The amount of water to meet this requirement is estimated at approximately $450 \mathrm{~kg}$. The water recovery system is responsible for providing this water in addition to that needed by the crew for daily consumption. To accommodate this, the water recovery system will use a combination of both stored and recovered water.

Two large, $450 \mathrm{~kg}$ capacity tanks will serve as storage for water. One tank will be launched full to provide the recharge water for the MPCV and the MMSEV, and the second tank will be launched empty to be filled with the extra water produced during the mission by the water processing system.

The water processing system utilizes the SOA ISS physiochemical Water Processing Assembly (WPA) that contains multi-filtration and ion-exchange beds to process all of the waste streams, which include galley and hygiene water, product water from the urine processor, and water extracted from the waste containment system (through Lyophilization of human waste and brine and Heat Melt Compaction of trash). Refer to Figure 3. It should be noted that although laundry was considered early in the design process, as the requirements matured, it was determined clothing would be stored. Thus, the final design concept does not include wash water from a laundry system.

Unlike the ISS Urine Processing Assembly that uses Vapor Conpression Distillation, athe DSH design uses a modified Urine Processing Assembly (UPA) with Cascade Distillation System (CDS) as the primary urine processor. The product of the UPA w/CDS is then filtered, oxidized, and added to the waste water tank for final processing by the WPA. While the calcium in urine limits distillation processes between $70-85 \%$ recovery system recycles all of the water necessary per day to sustain the crew and produces between 1.6 to $2.3 \mathrm{~kg}$ of excess water per day ${ }^{\S \S}$, respectively, depending upon the percent recovery.

Finally, the product water tank of the water recovery system will be launched full, with about three days worth of water (85 kg), to serve as a buffer when the crew needs to perform maintenance or repair on the UPA or WPA. Similarly, the water water tank is also sized to store three days worth of water.

\section{Waste Containment System}

The Waste Containment System collects and disposes of wet and dry trash and fecal waste, as well as controls the odor of urine. This system also reclaims the water from the urine, fecal waste, and wet trash. Analysis determined the collection of the brine from the trash and fecal waste is essential to ensure adequate water recovered per day for the defined mission. Approximately $1 \mathrm{~kg}$ of water can be reclaimed per day from the trash and fecal waste. Without the brine from trash and solid waste, only 0.5 to $1 \mathrm{~kg}$ of excess water is extracted per day from other waste streams.

Human waste is collected in two ways: with a urine receptacle and a compaction potty. The urine system collects the urine via a receptacle, and the collected urine can then be stored in a tank that contains pretreat. A spin separator separates the urine and air and filtration is used to control odor and to collect minerals and organic deposits from clogging the lines or the equipment in the system.

The fecal waste system has adopted the MPCV manual compaction potty, which consists of a collection bag, a mode for manual compaction, a fan, and filtration. The DSH is an optimal place to use the MPCV potty as it provides commonality of hardware across vehicles and allows for the DSH to take advantage of development costs incurred by MPCV.

Several questions were raised during the development of the design in an attempt to minimize the number of stowage containers by drying the waste in place. This is forward work to be conducted. It should also be noted that the fecal waste and the wet trash would utilize the same method to dry and compact the waste, and the dry, compacted waste will then be stowed.

\section{Pressure Control System}

The pressure control system design was based upon the following assumptions:

\footnotetext{
\# The ECLS Distillation Down Select has recognized the potential for CDS to improve beyond the ISS recovery performance.

$\$ \$$ The estimated amount of water produced is based upon operating the Sabatier continuously with both hydrogen provided from the OGA and from stores.
} 
1) Feeding cabin leakage for the 825 unmanned portion (DSH volume) and 388 manned portions (DSH, MPCV, and MMSEV volumes).

2) Replenishing MPCV with 11 days worth of gas usage from launch transit immediately upon docking.

3) Replenishing MMSEV: for 2 Full represses, 4 partial represses (8.3 to 10.2 psia), and 4 EVAs.

4) Providing for metabolic consumption for a crew of four (based upon the metabolic consumption with exercise $)^{10}$.

Based upon these assumptions, the total quantity of oxygen and nitrogen needed to support the mission was identified as $1545 \mathrm{~kg}$ and $281 \mathrm{~kg}$, respectively, although all of the metabolic $\mathrm{O}_{2}$ will be provided by the OGA. With these numbers (tank starting pressure and tank ambient temperature), the tanks were then sized using a parametric algorithm developed by the HAT Altair ECLSS team. The algorithm takes data from multiple suppliers to estimate the tank size based on the parameters of volume and pressure ${ }^{11}$, and it resulted in a PCS containing five, $100 \mathrm{~kg}$ tanks of low pressure $\mathrm{O}_{2}$ and three, $100 \mathrm{~kg}$ tanks of nitrogen $\left(\mathrm{N}_{2}\right)$.

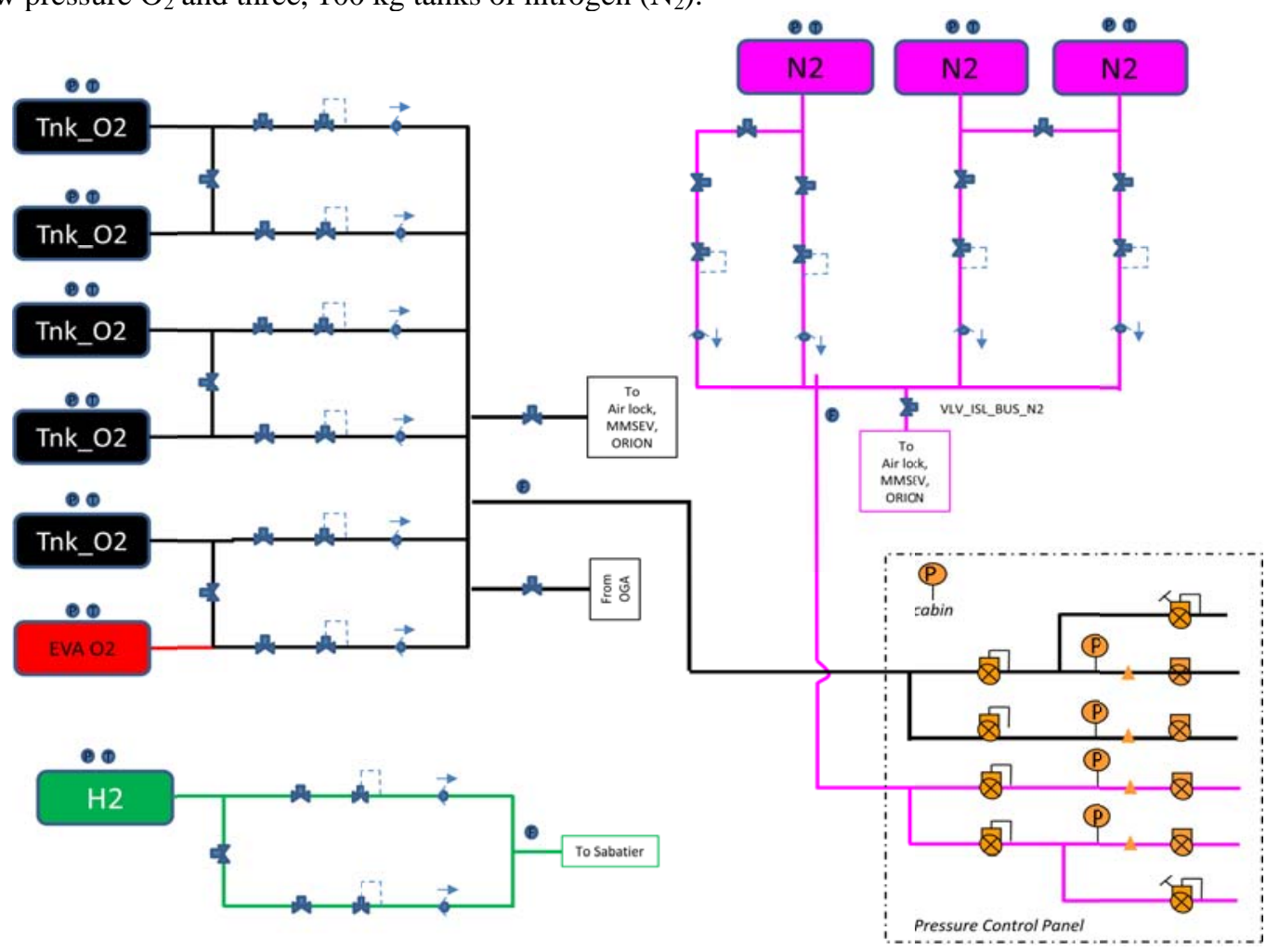

Figure 4. Pressure Control System Concept.

\section{E. Fire Detection and Response System}

The Fire Detection and Response System (FDRS) is essential to detect, annunciate, and effect a response to a fire on the DSH during both manned and unmanned portions of the mission. The FDRS is separated into three categories: detection, suppression, and recovery. The same study that evaluated the post-fire response (discussed in Section III above) also evaluated detection and suppression options and recommended a combined/layered approach for each.

The fire detection system will provide thermal sensing and fault detection circuitry to sense over temps or current spikes within hardware and shut down power to the hardware automatically. This system would also be capable of automatically cutting off ventilation to the affected area and routing that area to post-fire clean up hardware, as discussed earlier, once the fire has been extinguished. Additionally, smoke detectors will be placed on each floor and inside high-risk enclosed racks - those containing flammable materials. Finally, ambient trace gas contingency analyzers will also be included as a mode of fire detection.

Fire suppression takes advantage of the automatic power isolation and ventilation cutoffs systems designed as part of the detection system. Furthermore, a portable fire extinguisher could be used to extinguish the fire and one 
will be required per floor. Fixed fire suppression should be considered in the event the vehicle is unmanned or the crew is unable to take action.

\section{F. Ventillation}

In order to provide sufficient air supply to each of the four floors within the DSH, the Air Revitalization System will use two 400 cubic feet per minute (cfm) blowers. Nominally, each blower will supply the air flow for two of the floors, with each set balanced by one higher demand floor and one lower demand floor (refer to Figure 5). Each floor will have four supply and four return vents, with diverters on each of the supply vents to allow the crew to adjust the airflow to individuals areas of the floor. This local control is especially important in the crew quarters; however, no diverter will be able to be completely closed to preclude localized pockets of trace gases from developing. A system bypass is also provided to prevent deadheading a blower.

Filtration occurs at the inlet from the return air, and the post-fire clean up hardware is designed immediately downstream of the blowers. Cabin temperature control is provided by two heat exchangers, one downstream of each blower. The DSH is required to provide $100 \mathrm{cfm}$ ventilation for both the MPCV and MMSEV while there vehicles are docked. At this time, the hatches are not being designed to provide hard interfaces for this ventilation. Instead, supply ports have been designed near the airlocks to connect the umbilicals for each vehicle.

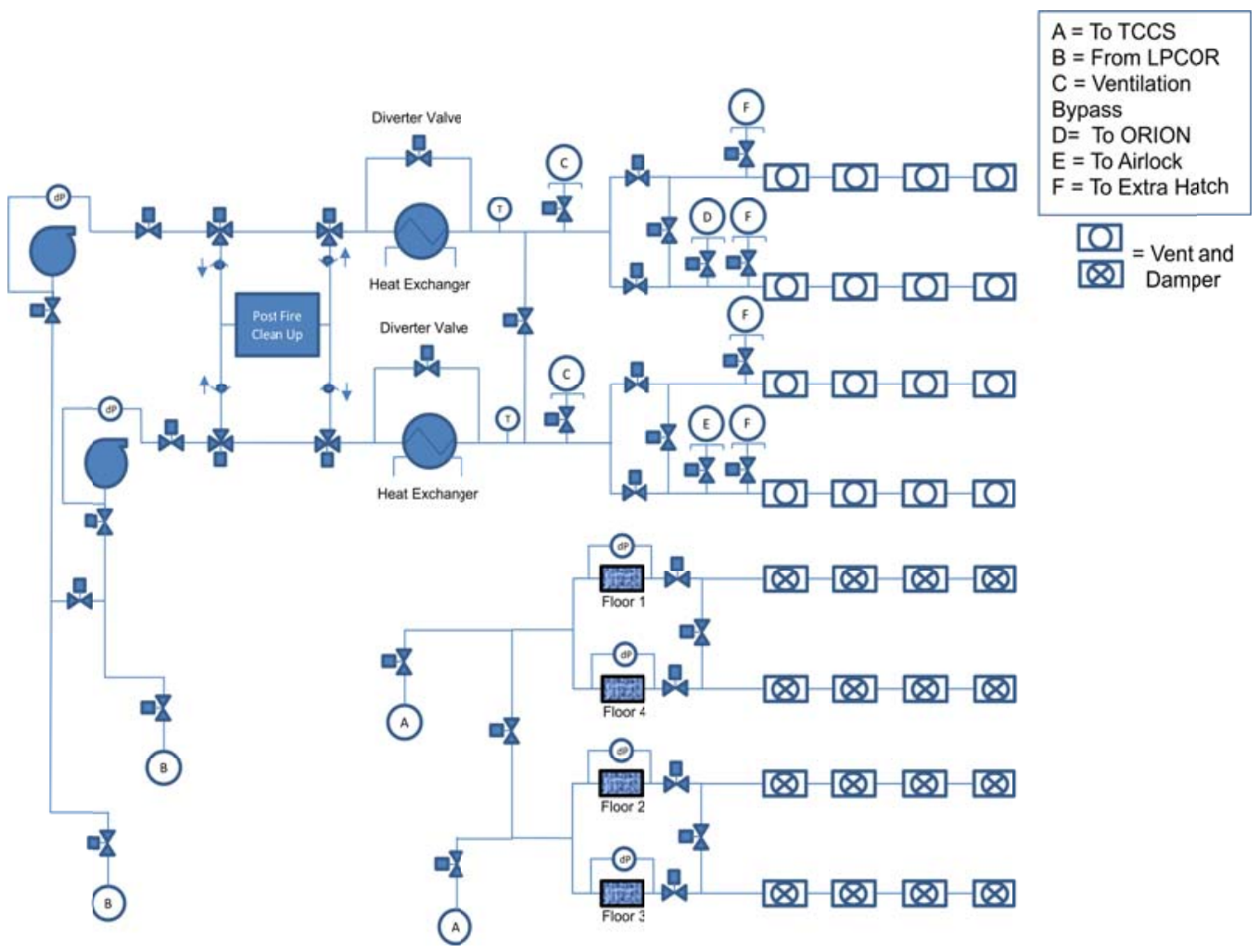

Figure 5. Deep Space Habitat Ventillation System Concept

\section{G. EVA Support}

Initially, the concept of operations for the stack of vehicles (MPCV, DSH, and MMSEV) had nominal EVAs performed from the MMSEV. With that, the original requirements for EVA support from the DSH only included providing high pressure oxygen recharge, low pressure oxygen recharge for the suit port seals, and Liquid Cooling Garment water resupply for the MPCV and low pressure oxygen recharge for the MMSEV - as MMSEV has its own oxygen compressor and contingency repress gases. However, as the DSH design concept matured, it was determined by the vehicle team that while nominal EVAs would still be performed from the MMSEV, the DSH needs to provide for contingency EVAs from the DSH itself when the MMSEV is not docked in the event that the MPCV were to sustain a hull breach. 
To accommodate this, the DSH will need at least two suit loop connections for the Advanced Crew Escape Suits and air and water systems provisions for the EVA capable suits (consisting of vacuum umbilicals for the Rapid Cycle Amine $\mathrm{CO}_{2}$ removal system and either vacuum for the Spacesuit Water Membrane Evaporator or a cooling loop).

\section{H. ECLSS Responsibilities per Floor}

The DSH vehicle design utilizes a vertical shell divided into four floors with a center core used as the crew pass through from one floor to the next and each floor has been assigned a specific function (refer to Figure 6). While the ECLSS needs to provide pressure control, ventilation, and atmospheric control to all of these floors simultaneously, some of the floors have additional requirements from ECLSS, as discussed below.

Since deck 1 includes the galley, the ECLSS must provide potable hot and cold water taps for meal preparation and general consumption. This area must also have provisions for wet and dry trash stowage, and the Heat Melt Compaction may be located on this floor in order to eliminate the need for the crew to haul trash to other floors for processing.

Deck 2 houses the individual crew quarters and has the least amount of services from the ECLSS. There has been considerable discussion regarding locating stored water in this area to provide radiation shielding for the crew. As the ECLSS intends to launch $450 \mathrm{~kg}$ of water, this is a possible location for this water, although the exact means of storage (smaller water bags or larger tanks) have not yet been determined. Additional work is needed in this area to discuss recirculation paths and biocide dosing, interconnects between the water storage system and the WRS, MPCV, and MMSEV, as well as redundancy for Loss of Crew (LOC)/Loss of Mission (LOM) considerations.

The majority of the life support hardware with crew interface will be located on the third deck. The waste/hygiene compartment is located on this floor and will provide a hand wash system, body wash system, and commode and urinal systems. Wet trash from wipes as well as human waste will be stowed, if not processed, on this floor. Additionally, interfaces to ventilation for the MMSEV as well as EVA systems will be located on this floor.

Deck 4 is dedicated for stowage and subsystem equipment. The vehicle team would like noisy and dangerous equipment as far away form the crew quarters as reasonable, and although the specific equipment to be located in this area has not yet been determined, this could be the location of the ARS blowers, the Sabatier, the Lyophilization system, and the urine processing hardware. The ventilation umbilical for the MPCV will also be connected to the ARS on this floor. 


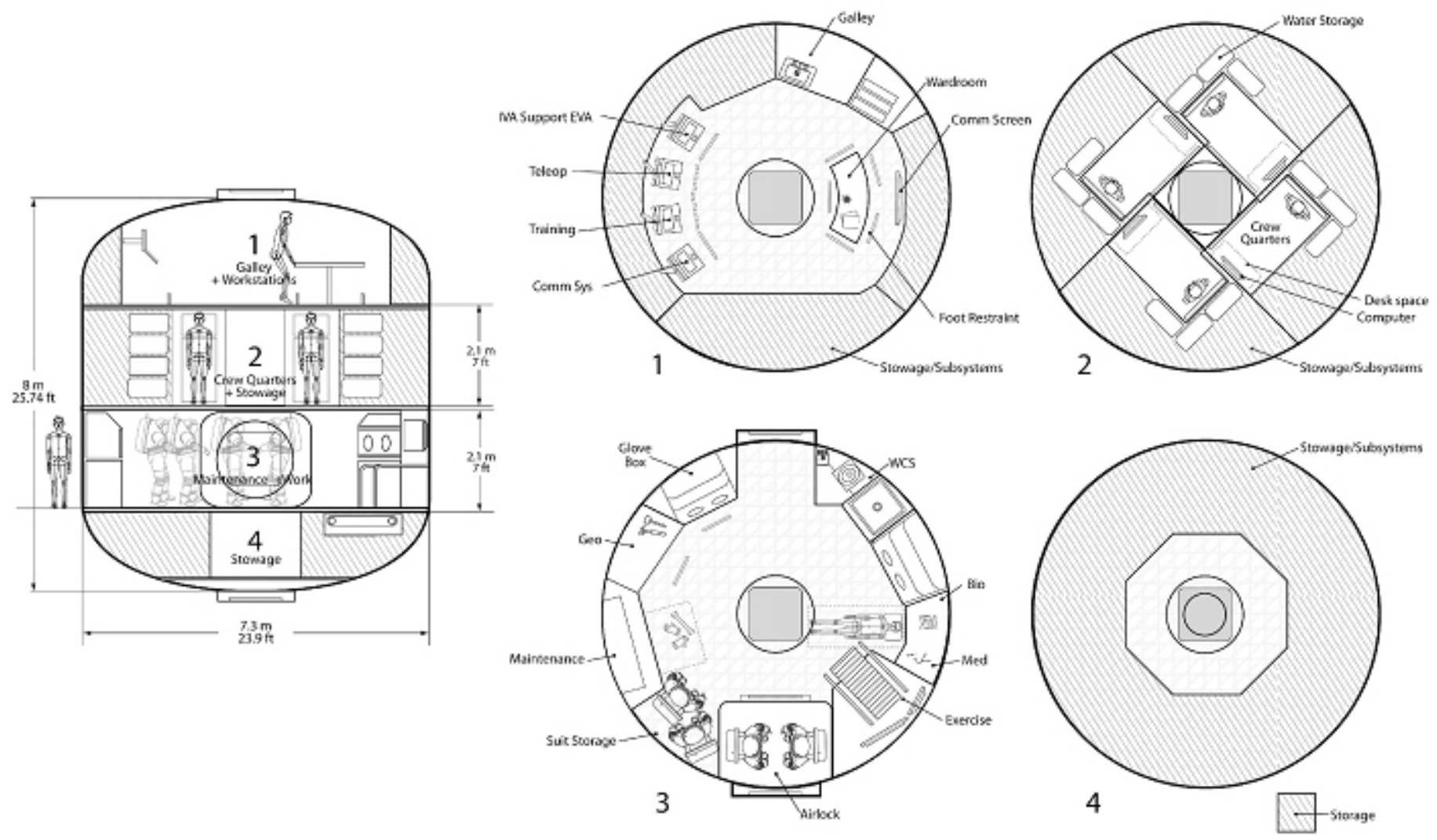

Figure 6. Deep Space Habitat Vertical Orientation Layout

\section{LOC/LOM Redundancy}

The Deep Space Habitat team began with a "rule-based" redundancy plan for the first iteration and intended to perform probabilistic risk assessment on the design in the next iteration to create a risk-informed design. In this mission, a quick abort home was not considered a reasonable response to a failure. As a result, the initial DSH life support design started with two-fault tolerant functionality for loss of crew and single fault tolerant for loss of mission.

The function of "provide atmosphere" is one which would most quickly lead to loss of crew in the event of a failure. Failure to recharge MMSEV tanks to explore the asteroid constitutes loss of mission. Pressure regulators and controllers were installed in redundant, parallel paths. Using more, small nitrogen tanks means that two can fail and still leave enough nitrogen for the mission while increasing mass by a smaller fraction than using 3 systems each sized for the whole mission. Oxygen supply could either be provided through storage tanks or through electrolysis from water. Installing three oxygen generators using recycled water was found to be more efficient than providing stored oxygen for the entire mission with redundant tank quantities. Some oxygen must always be available in a high pressure tank for EVA and MMSEV recharge, and this oxygen could also be used temporarily during the troubleshooting period in the event of an OGA failure.

The function of "provide water" could lead to a loss of crew state after a failure, but in a survival case, a lower water use rate $(2 \mathrm{~L} / \mathrm{CM} / \mathrm{d}$ instead of $2.9 \mathrm{~L} / \mathrm{CM} / \mathrm{d})$ could be implemented. Failure to provide water for the MMSEV recharge causes a loss of mission case. Storing water for the entire mission would be a prohibitively large mass. Instead, recycling water from waste is more cost effective but means that many technologies are now critical to the survival of the crew. Even with recycling systems in place, there are stored volumes of water in the vehicle. The mass balance impacts of technology failure and stored water must be considered together. 
An analysis of the mass balance was performed to see how critical each functions were at various points in the mission. The wastewater tank and potable water tank for the water processor is assumed to have several days capacity, capable of handling brief downtimes for maintenance or replacing components. Another tank of water in the vehicle stores water for MMSEV recharge. Since that recharge is a fairly large amount of water delivered quickly, it cannot be supplied directly from the water processor. To avoid loss of mission from a single failure, two tanks and parallel delivery paths (regulators, valves) are required. The water processor provides potable water from condensate and other wastewater and must have three parallel processors to be two fault tolerant.

Other technologies, like the urine processor, Sabatier reactor, or waste dryer provide gray water (not potable) to the water processor. The urine processor provides the largest amount of water of the three, estimated at $3.5-4 \mathrm{~kg} / \mathrm{d}$. If the urine processor fails early in the mission, but Sabatier and waste drying are still working, there is still not enough water to survive the rest of the mission even if water is left in an MMSEV recharge tank for use. Thus, the urine processor must be two-fault tolerant and have three strings. The Sabatier reactor provides more water than waste drying but also requires more mass and power. If a Sabatier reactor fails, even if the waste dryer is operating, the crew would have to use water reserved for MMSEV recharge to survive. Thus, loss of the Sabatier is loss of mission, and it must have redundant components. But if both Sabatier systems fail and the MMSEV tanks and waste drying functions operate, the crew can survive. The waste dryer is more cost effective for survival than Sabatier, but since the water produced by it is assumed to be lower, failure of the waste dryer does not lead to loss of mission. Therefore, redundant strings are not necessary.

If all of the water processing hardware operates, excess clean water is produced. With this knowledge, only one volume of MMSEV recharge water needs to be available at launch. Without hardware failures, the second tank will be filled with excess clean water over time before the need date. This also leaves the crew with one tank of water even after the MMSEV recharge has occurred. Thus, a single point failure to any recycling function or MMSEV tank should not result in loss of mission, and no two failures in combination can leave the crew without enough water to survive.

\section{Forward Work}

Work is still needed before NASA can confidently build a life support system for a Deep Space Habitat that will meet all the needs. While this study effort has ended, other organizations are continuing efforts, with the biggest questions remaining are in the reliability of the hardware. Currently other studies are examining probabilistic assessments of state of the art regenerative life support systems, and their lessons learned should be brought to bear on the redundancy and emergency strategy in this design. Technology development groups are refining performance estimates and trying to increase the robustness of their technologies and increase system reliability. In parallel, parametric assessments of other mission architectures continue, and the detailed lessons learned from these studies should be brought into this design as well. As results from all these efforts are revealed, the system design should be refined to create the safest, most reliable, and most efficient way to provide life support for crews venturing beyond Earth orbit.

\section{Nomenclature}

$\begin{array}{ll}\text { ALSSAT } & \text { Advanced Life Support Sizing and Analysis Tool } \\ \text { ARS } & =\text { Air Revitalization System } \\ \mathrm{CDRA} & =\text { Carbon Dioxide Removal Assembly } \\ \mathrm{CDS} & =\text { Cascade Distillation System } \\ \mathrm{Cfm} & =\text { cubic feet per minute } \\ \mathrm{CH}_{4} & =\text { Methane } \\ \mathrm{CHX} & =\text { Condensing Heat Exchanger } \\ \mathrm{CM} & =\text { Crew member } \\ c_{P} & =\text { Power equivalency for ESM analysis, }[\mathrm{kg} / \mathrm{kW}] \\ c_{Q} & =\text { Cooling equivalency for ESM analysis, }[\mathrm{kg} / \mathrm{kW}] \\ c_{t} & =\text { Crew-time equivalency for ESM analysis, }[\mathrm{kg} / \mathrm{CM}-\mathrm{hr}] \\ c_{V} & =\text { Volume equivalency for ESM analysis, }\left[\mathrm{kg} / \mathrm{m}^{3}\right] \\ \mathrm{CO}_{2} & =\text { Carbon Dioxide } \\ \mathrm{D} \& \mathrm{R} & =\text { Depressurizing and Repressurizing } \\ \mathrm{DSH} & =\text { Deep Space Habitat }\end{array}$




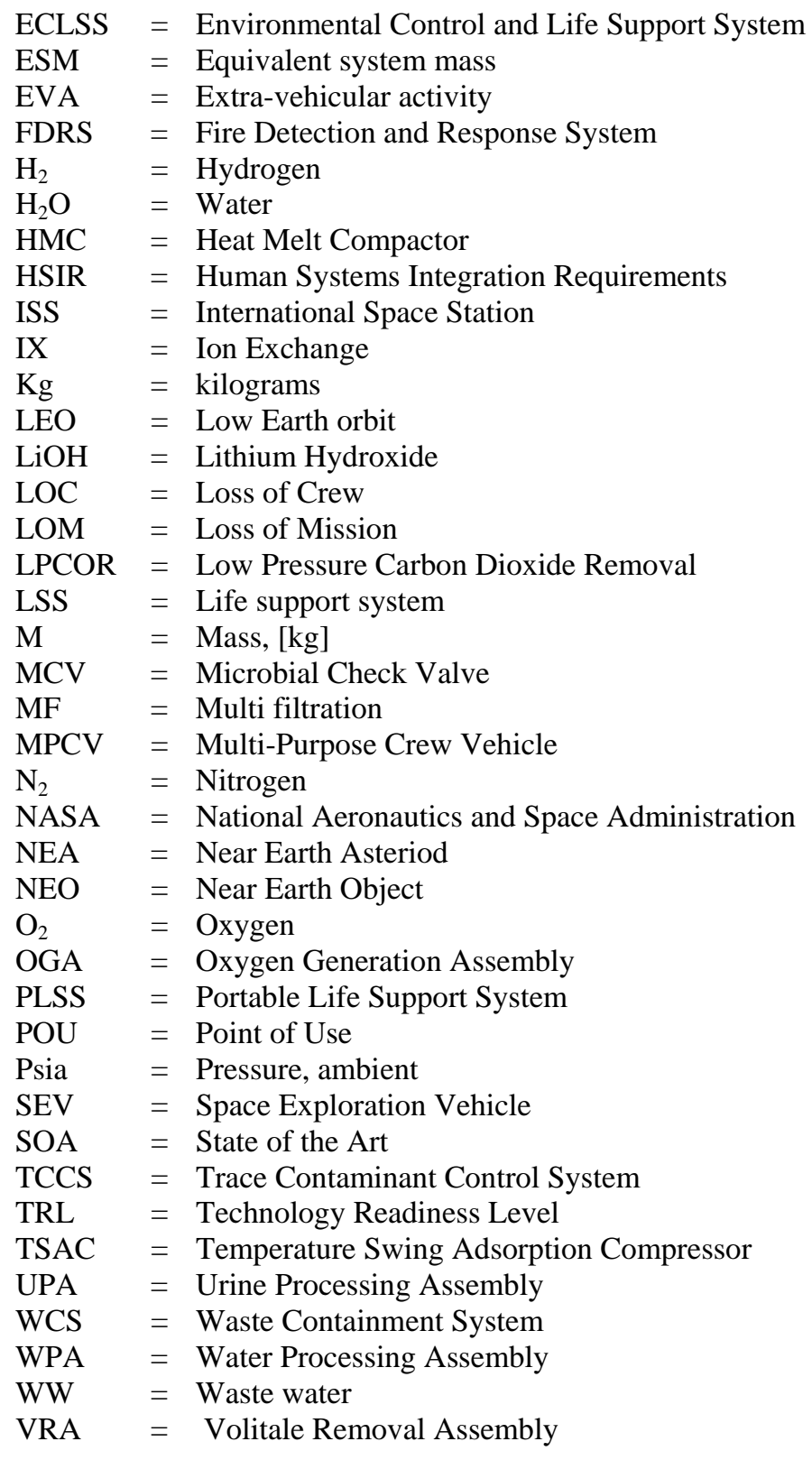

\section{References}

${ }^{1}$ Levri, J. A., Vaccari, D. A., and Drysdale, A. E., “Theory and Application of the Equivalent System Mass Metric,” $30^{\text {th }}$ International Conference on Environmental Systems, SAE, Toulouse, France, 2000, Paper No. 2000-01-2395.

${ }^{2}$ Levri, J. A., Drysdale, A. E., Ewert, M. K., Fisher, J. W., Hanford, A., Hogan, J. A., Joshi, J. A., and Vaccari, D. A., “Advanced Life Support Equivalent System Mass Guidelines Document,” Tech. rep., NASA/TM-2003-212278, 2003.

${ }^{3}$ Jones, H. W., "Using Radar Charts to Select Life Support Technology,” 40th International Conference on Environmental Systems, AIAA, Barcelona, Spain, 2010, Paper No. AIAA 2010-6015.

${ }^{4}$ Jones, H. W., "Breakeven Mission Durations for Physicochemical Recycling to Replace Direct Supply Life Support," 37th International Conference on Environmental Systems, SAE, Chicago, IL, 2007, Paper No. 2007-01-3221.

${ }^{5}$ Williams, D. E., Dake, J. R. and Gentry, G.A., "International Space Station Environmental Control and Life Support System Status 2009-2010”, 40th International Conference on Environmental Systems, Barcelona, Spain, 2010, Paper No. AIAA-20106180-792.

${ }^{6}$ Varghese M. M. et al., "Development Status of a Lower-Power CO2 Removal and Compression System for Closed-Loop Air Revitalization”, 40th International Conference on Environmental Systems, Barcelona, Spain, 2010, Paper No. AIAA-20106060 . 
7 “Distillation Technology Comparison for Spacecraft Applications”, NASA Johnson Space Center, Houston, Texas, April 2010.

${ }^{8}$ Jeng, F.F., “Assessment of Improvement in Air Drying and Moisture/ $\mathrm{CO}_{2}$ Removal Technologies for Carbon Dioxide Removal Assembly (CDRA)”, NASA Johnson Space Center, Houston, Texas, August 2011, ESCG-4470-11-TEAN-DOC-0051.

${ }^{9}$ Jones, H., “Design and Analysis of a Flexible, Reliable Deep Space Life Support System” NASA AMES Research Center, California, September 2011.

10 “Constellation Program Human-Systems Integration Requirements”, CxP 70024D Appendix E, NASA Johnson Space Center, Houston, Texas, December 11, 2009

${ }^{11}$ Anderson, M.S., Curley, S., Rotter, H., Stambaugh, I., Yagoda, E.“Altair Lander Life Support: Design Analysis Cycles 4 and 5”, $41^{\text {st }}$ International Conference on Environmental Systems, Portland, OR, 2011, Paper No. AIAA- 